Discussion Paper No. 10-059

\title{
Expected Utility Theory and the Tyranny of Catastrophic Risks
}

Wolfgang Buchholz and Michael Schymura

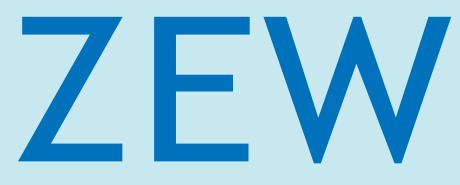

Zentrum für Europäische Wirtschaftsforschung $\mathrm{GmbH}$

Centre for European

Economic Research 
Discussion Paper No. 10-059

\section{Expected Utility Theory and the Tyranny of Catastrophic Risks}

Wolfgang Buchholz and Michael Schymura

Download this ZEW Discussion Paper from our ftp server:

ftp://ftp.zew.de/pub/zew-docs/dp/dp10059.pdf

Die Discussion Papers dienen einer möglichst schnellen Verbreitung von neueren Forschungsarbeiten des ZEW. Die Beiträge liegen in alleiniger Verantwortung der Autoren und stellen nicht notwendigerweise die Meinung des ZEW dar.

Discussion Papers are intended to make results of ZEW research promptly available to other economists in order to encourage discussion and suggestions for revisions. The authors are solely responsible for the contents which do not necessarily represent the opinion of the ZEW. 


\section{Das Wichtigste in Kürze}

Die Erwartungsnutzentheorie (EUT) kann nicht nur für Entscheidungen auf individueller Ebene angewandt werden, sondern auch aggregiert in ethischen Entscheidungssituationen, wie zum Beispiel in Kosten-Nutzen-Analysen bei der Evaluierung klimapoltischer Politik die vor allem zukünftige Generationen betreffen. In diesem Zusammenhang stellt sich die Frage, inwiefern die die EUT mit katastrophalen Ereignissen mit extrem niedriger Wahrscheinlichkeit umgehen kann. In unserer Arbeit zeigen wir die Schwierigkeiten der EUT beim Umgang mit katastrophalen Ereignissen auf. Falls man eine hinreichende Risikoaversion annimmt, tritt eine "Tyrannei der katastrophalen Risken" (TCR) auf. Die Projektevaluation kann dann von extrem unwahrscheinlichen Ereignissen dominiert werden. Falls die angenommene Risikoaversion sehr gering ist, kann es passieren, das solche katastrophalen Ereignisse überhaupt keinen Einfluss auf das Ergebnis haben, was aus ethischer Perspektive genauso bedenklich ist. Der Artikel trägt bei zu der Literatur über die Paradoxien der EUT, wie z.B. dem Allais-Paradoxon oder Martin Weitzmans "dismal theorem". Wir behandeln den spezifischen Fall von katastrophalen Ereignissen mit sehr hohen Schäden und sehr geringer Eintrittswahrscheinlichkeit, wie es etwa beim Klimawandel der Fall sein kann. Nach einem einleitenden Teil zeigen wir in heuristischer Art und Weise, dass es aus ethischen Gründen notwendig sein kann, die Zahlungsbereitschaft zur Vermeidung von Extremereignissen nach oben zu begrenzen. Wir formalisieren dann die sogenannte "Tyrannei der katastrophalen Risiken" (TCR) und zeigen auf, dass das Auftreten der TCR fundamental von der Wahl der zugrunde liegenden Nutzenfunktion abhängt. Wir folgern, dass man eine unrealistisch niedrige Risikoaversion annehmen müsste, um die TCR zu vermeiden. Am Ende bennenen wir die Alternativen zur EUT, die allerdings katastrophale Risiken noch mehr berücksichtigen und so das Problem der TCR noch verschärfen können. 


\section{Executive Summary}

Expected Utility (EU) theory is not only applied to individual choices but also to ethical decisions, e.g. in cost-benefit analysis of climate change policy measures that affect future generations. In this context the crucial question arises whether EU theory is able to deal with "catastrophic risks", i.e. risks of high, but very unlikely losses, in an ethically appealing way. In this paper we show that this is not the case. Rather, if in the framework of EU theory a plausible level of risk aversion is assumed, a "tyranny of catastrophic risk" (TCR) emerges, i.e. project evaluation may be dominated by the catastrophic event even if its probability is negligibly small. With low degrees of risk aversion, however the catastrophic risk eventually has no impact at all when its probability goes to zero which is ethically not acceptable as well. Our work contributes to the literature about the paradoxes of EU theory, like e.g. the Allais paradox or Martin Weitzmans "dismal theorem". In this spirit we will consider the specific case of catastrophic risks where extremely high losses occur with a very low probability like for example extreme forms of climate change. After introducing the problem we give some heuristic motivation and show, that it can be an ethical imperative that the willingness to pay for avoiding catastrophic risks should be limited. Then we formalize the so-called "Tyranny of Catastrophic Risks" (TCR) and show that it crucially depends on the type of the underlying utility function whether bad but very unlikely outcomes may dominate the results. Furthermore we conclude that one would have to assume an implausibly low degree of risk aversion to exclude TCR. Finally we disucss shortly alternatives to EU theory, but the intention of most of these approaches is to give catastrophic risks more attention instead of less such that the TCR might even be aggravated. 


\title{
Expected Utility Theory and the Tyranny of Catastrophic Risks
}

\author{
Wolfgang Buchholz*and Michael Schymura ${ }^{\dagger}$
}

August 25, 2010

\begin{abstract}
Expected Utility theory is not only applied to individual choices but also to ethical decisions, e.g. in cost-benefit analysis of climate change policy measures that affect future generations. In this context the crucial question arises whether EU theory is able to deal with "catastrophic risks", i.e. risks of high, but very unlikely losses, in an ethically appealing way. In this paper we show that this is not the case. Rather, if in the framework of EU theory a plausible level of risk aversion is assumed, a "tyranny of catastrophic risk" (TCR) emerges, i.e. project evaluation may be dominated by the catastrophic event even if its probability is negligibly small. With low degrees of risk aversion, however the catastrophic risk eventually has no impact at all when its probability goes to zero which is ethically not acceptable as well.
\end{abstract}

Keywords: Utilitarianism, Expected Utility Theory, Catastrophic Risks JEL-Classification: Q54

\footnotetext{
*Affiliation: University of Regensburg

${ }^{\dagger}$ Affiliation: Centre for European Economic Research (ZEW), Mannheim
} 


\section{Introduction}

Expected Utility (EU) Theory still provides the standard theoretical tool for cost-benefit analysis under conditions of risk which, in the context of environmental economics, is used to assess whether conservation or pollution abatement measures with uncertain consequences are economically beneficial or not. For a long time this approach, however, has come under attack. So, in many circumstances, observable behavior of actual people does not conform to the predictions of EU theory. Beginning with Allais (1953) [1] and Ellsberg (1961) [9] it has been shown by a lot of experiments that, regularly, decisions under risk are subject to paradoxes and anomalies such that individuals act not in accordance with the axioms of EU theory.

Besides this well-known criticism there is another strand of objections against EU theory which is, in some sense, related to those of behavioral economics but conceptually different. So, in some cases, it is already suggested by theoretical reasoning and thought experiments ("at the desk and not in the lab" ) that in many situations strict application of EU theory would produce results that contradict "plausibility", i.e. that do not reflect intuitive expectations and seem hard to accept. A prominent example for this is Rabin (2000) [19] who has first shown by a purely formal argument that moderate risk aversion w.r.t. to small lotteries would, if consistently applied, lead to an immoderate high degree of risk aversion at the large. In a similar vein, standard properties of von Neumann Morgenstern utility functions (as risk aversion as such and decreasing absolute risk aversion in particular) initially were motivated by means of introspection and not by conducting experiments in a systematic way (see Arrow, 1963 [2]).

Even though such considerations refer to behavior of individuals they are also of relevance in another context. So there is long tradition to apply EU theory not only to individual decisions under risk but also to ethical choices concerning the society as a whole (see already Harsanyi, 1955 [12]) $)^{1}$. This ethical dimension of EU theory is not only of a mere abstract theoretical interest but has much importance for real-life cost-benefit analysis just when, as in the field of climate change policy (see e.g. Stern, 2006 [22]), the interests of future

\footnotetext{
${ }^{1}$ For a critical assessment of Harsanyi's ethical interpretation of EU theory see Roemer (1996, pp. $147-152)$
} 
generations are to be given due attention. In the ethical context plausibility of results obtained through the EU approach can get some new and special meaning since sensibility at the individual level may transform into ethical acceptability at the collective level. So smoothing income across different states of nature which is as an implication of decreasing marginal utility of income, i.e. risk aversion, not only seems to be rational and prudent from a personal viewpoint but, from the standpoint of the society or an "ethical observer", also serves the purpose to justify a more equal distribution of income and wealth among different individuals or generations.

Concerning application of EU theory to ethical decisions a main question is which normative objectives ("values") can be incorporated by this approach. So, in particular, it can be asked whether ethically appealing results can be generated by using specific von Neumann-Morgenstern (vNM) utility functions. If this is possible, pursuing certain normative ideas would give some legitimate reason to restrict the class of admissible utility functions, e.g. make different degrees of risk aversion more or less acceptable. If, however, it is not possible to exclude ethically non palatable outcomes by adopting particular utility functions or if for different types of ethical decisions not the same type of utility functions were obtained this would indicate an only limited applicability of EU theory for making ethical choices.

In this spirit we will now consider the specific case of catastrophic risks where extremely high losses occur with a very low probability. It is a common belief in science that this describes the situation mankind is confronted with in the context of climate change and biodiversity loss. The specific climate change risks consist of several linked parts: there are severe risks in predicting effects of a changing climate (scientific risks), uncertainties about effective policy measures (policy risks) and the size of abatement cost (economic risks). These uncertainties can be additive or even multiplicative. Weitzman's [25] analysis shows that in the framework of EU theory "fat-tailed" risks yield results that are in sharp conflict to ethical intuition. So, according to EU theory society would always be willing to pay an extremely high price for avoiding such low likely catastrophes such that almost any economic progress might be prevented. In this paper we will consider some variant of this "dismal theorem" (Weitzman, 2009 [24]) and 
show by very simple arguments that EU theory indeed has much problem to handle such catastrophic risks in an ethically satisfactory way. We thus confirm that, from the ethical perspective, fundamental "limits of expected-utility analysis" (Dietz and Maddison, 2009, 301 [8]) exist so that alternative approaches for dealing with catastrophic risk might seem to be more appropriate (Heal, 2008 [13] and Chichilnisky, 2000 [5], 2009 [6]). But unlike Chichilnisky (2000 [5] and 2009 [6]) we do not purport the view that EU theory is too insensitive w.r.t. rare events with severe consequences but, in contrast, that utility functions that show a sensible degree of risk version may entail a dominance or even "tyranny" of catastrophic risks.

The paper is organized as follows: In Section 2 we give a heuristic motivation for the problem which is caused for EU theory through catastrophic risks. In Section 3 we then show, by considering sequences of projects with discrete probability distributions, that the dominance ("tyranny") of such catastrophic risks can only be avoided by applying utility functions with an unusual low degree of risk aversion. If we instead consider single risky projects over an infinite number of states this tyranny of catastrophic risks is interpreted in a different way. It then means that expected utility may become infinite even though the expected value of payoffs is finite. In Section 4 it is demonstrated that also in this situation unacceptable outcomes can only be avoided in the framework of EU theory when degrees of relative risk aversion smaller than one are accepted which seems hard to digest. 


\section{Some Heuristic Motivation}

To keep the main argument as simple as possible we first consider a class of projects (or "lotteries") in which there are only two outcomes ("states of nature"). The payoff in the good state is fixed as $c_{1}=1$. The payoff in the bad state $c_{2}$ instead varies and approaches $\underline{c}_{2}=0$ as its lower bound. Assuming $\underline{c}_{2}=0$ as the very worst outcome is a normalization that is common in EU theory. It indicates an absolute catastrophe, e.g. complete extinction of mankind by an extreme form of climate change. Levels of $c_{2}$ that lie between 0 and $c_{1}$ can, e.g., be interpreted as the share of population or world income that would remain after an environmental breakdown had happened. The probability of the bad outcome is denoted $p_{2}$, which will become very small when the payoff in the bad state approaches zero. So, e.g., we have $p_{2}=10^{-6}$ and at the same time $c_{2}=10^{-7}$. In such a situation ethical intuition would demand that such adverse, but very unlikely consequences of climate change are taken into account to some degree but only within reasonable limits. This in particular means that very bad outcomes with, however, low probabilities should not let the certainty equivalent payoffs of the projects go to zero. Or, to put it in another way: It seems to be an ethical imperative that the willingness to pay for avoiding catastrophic, but extremely rare losses should be limited and kept away from zero as it is obviously the case in individual real-life decisions. No reasonable person will stay at home all time long only to protect herself from the danger of being killed in a traffic accident or being hit by an airplane crash. Otherwise, a "tyranny of catastrophic risks (TCR)" would emerge which, at the individual level, would be paralyzing normal life and be outright crazy. TCR at the level of society would mean that the "social planner" (or ethical observer) almost completely neglects the prospects of attaining the good state with high wealth and instead tolerates that the economy runs into poverty only to avoid a still worse but extremely unlikely outcome. In the next sections it will be examined how EU theory is able to cope with such situations, i.e. to exclude that project evaluation leads to such implausible and ethically mistaken results. 


\section{The Tyranny of Catastrophic Risks for Se- quences of Projects}

As common in EU theory the risk preferences of a risk-averse ethical observer are represented by a twice continuously differentiable $\mathrm{vNM}$ utility function $u(c)$ that is defined for all payoff levels $c>0$ and has $u^{6}(c)>0$ and $u^{\prime \prime}(c)<0$ everywhere. To simplify the exposition we will consider risky projects with a discrete probability distribution over $k+1$ states $i=1,2, \ldots, k+1$. A project's payoff in state $i$ is denoted by $c_{i}$. For any project $P=\left(\left(c_{1}, p_{1}\right) ; \ldots ;\left(c_{k+1}, p_{k+1}\right)\right)$, the certainty equivalent of $P_{c}$ is denoted by $m_{u}\left(P_{c}\right)$, i.e.

$$
u\left(m_{u}(P)\right)=\sum_{i=1}^{k+1} p_{i} u\left(c_{i}\right) .
$$

. The state $k+1$ indicates the catastrophic event whose probability $p_{k+1}$ may vary and eventually go to zero. To concentrate on the influence of different levels of $p_{k+1}$ on project evaluation we assume that the conditional probabilities $\bar{p}_{i}$ of the non-catastrophic states $i=1, \ldots, k$ in case of non-occurrence of the catastrophic event are constant. Given some $p_{k+1}$ the true probability of state $i=1 \ldots, k$ then is $p_{i}\left(p_{k+1}\right):=\left(1-p_{k+1}\right) \bar{p}_{i}$. For any exogenously given combination of conditional probabilities $\left(\bar{p}_{1}, \ldots, \bar{p}_{k}\right)$ and payoffs $\left(\bar{c}_{1}, \ldots, \bar{c}_{k}\right)$ in the "normal" non-catastrophic states we then define potentially catastrophic projects by $P_{c}\left(c_{k+1}, p_{k+1}\right)=\left(\left(\bar{c}_{1}, p_{1}\left(p_{k+1}\right) ; \ldots ;\left(\bar{c}_{k}, p_{k}\left(p_{k+1}\right) ;\left(c_{k+1}, p_{k+1}\right)\right)\right)\right.$ that depend on the probability $p_{k+1}$ and the payoff $c_{k+1}$ in the catastrophic state. If $p_{k+1}=0$ such a project coincides with the non-catastrophic project $P_{g}=\left(\left(\bar{c}_{1}, \bar{p}_{1}\right) ; \ldots ;\left(\bar{p}_{k}, \bar{c}_{k}\right)\right)$ that is defined over $k$ states. Loosely speaking, each project $P_{c}\left(c_{k+1}, p_{k+1}\right)$ is a mixture between the catastrophic event and the exogenously given $P_{g}$. We now use sequences $\left(P_{c}^{(n)}\right)_{n \in \mathbb{N}}=\left(P_{c}^{(n)}\left(c_{k+1}^{(n)}, p_{k+1}^{(n)}\right)\right)_{n \in \mathbb{N}}$ of potential catastrophic projects to give a precise definition for the TCR phenomenon. Then TCR can be characterized as follows:

Definition 1 Tyranny of catastrophic risks (TCR) holds for a given vNM utility function $u(c)$ if for any given $P_{g}$ there is a sequence of potentially catastrophic projects $\left(P_{c}^{(n)}\right)_{n \in \mathbb{N}}$ such that $\lim _{n \rightarrow \infty} p_{k+1}^{(n)}=0$ and simultaneously $\lim _{n \rightarrow \infty} m_{u}\left(P_{c}^{(n)}\right)=$ 0.

This Definition means that it is possible that the certainty equivalent payoff level, i.e. the payoff level the ethical observer accepts to get full insurance 
against risk, goes to zero even if the likelihood of the catastrophic event becomes arbitrarily small. Then the impact of the catastrophic event - irrespective of its probability and the payoff levels in the non-catastrophic states - is so great that it dominates the evaluation of the whole project. What is responsible for such an extreme sensitivity of project appraisal w.r.t. catastrophic risks will be shown by the following Proposition.

Proposition 1 TCR always prevails if the utility function $u(c)$ is unbounded below, i. e. $\lim _{c \rightarrow 0}=-\infty$.

Proof. We choose some sequence of payoffs $\left(c_{k+1}^{(n)}\right)_{n \in \mathbb{N}}$ with $\lim _{n \rightarrow \infty} c_{k+1}^{(n)}=$ 0 and $u\left(c_{k+1}^{(n)}\right)<0$ for all $n \in \mathbb{N}$. Then we define a corresponding sequence of probabilities by letting $p_{k+1}^{(n)}:=\left(-u\left(c_{k+1}^{(n)}\right)\right)^{-\alpha}$ for some arbitrary $\alpha \in(0,1)$ and any $n \in \mathbb{N}$. Since $\lim _{c \rightarrow 0}(-u(c))^{-\alpha}=0$ we clearly have $\lim _{n \rightarrow \infty} p_{k+1}^{(n)}=0$. For the limit of expected utility we get $\lim _{n \rightarrow \infty} \sum_{i=1}^{k} p_{i}\left(p_{k+1}^{(n)}\right) u\left(c_{i}\right)+p_{k+1}^{(n)} u\left(c_{k+1}^{(n)}\right)=$ $\sum_{i=1}^{k} p_{i} u\left(c_{i}\right)+\lim _{n \rightarrow \infty}\left(-\left(-u\left(c_{k+1}^{(n)}\right)\right)^{1-\alpha}\right)=-\infty$, which directly gives $\lim _{n \rightarrow \infty} m_{u}\left(P_{c}^{(n)}\right)=0$.

Proposition 1 in particular shows that it is not necessarily true that EU theory "underestimates the outcomes of small-probability events" and thus "is biased against certain environmental projects that are designed to prevent catastrophic events" (Chichilnisky 2000, p. 226 [5]). Rather, it crucially depends on the type of the underlying utility function whether very bad but simultaneously very unlikely outcomes may drag the certainty equivalent payoff level finally down to the minimum payoff level $(=0)$. If the utility function has no lower bound TCR becomes unavoidable. The relationship of unboundedness below to standard curvature properties of the utility function is obvious: A utility function is unbounded below if it is sufficiently risk averse. A precise sufficient condition for that is that for the Arrow-Pratt measure of relative risk aversion $\eta(c)=-\frac{u^{\prime \prime}(c) c}{u^{\prime}(c)}$ we have $\eta(c) \geq 1$ for all $c>0$ (see Gollier 2001 [11]).

That the degree of risk aversion of the underlying utility function is responsible for TCR is also highlighted by another observation. So any sequence of projects which leads to TCR criterion for some initially given utility function keeps this property for any other utility function with an overall higher degree of risk aversion. This is due to the general fact that higher risk aversion gives rise to lower levels of certainty equivalents for all risky projects (see e.g. Gollier, 
$2001[11])$.

Utility functions which have relative risk aversion $\eta(c)$ above one and thus imply TCR do not seem to be very extraordinary and special. They are even required to avoid other ethically undesired consequences as e.g. an extreme high savings rate and thus an unfair distribution between generations. As has been shown by Dasgupta (2008) [7] in the framework of a simple Ramsey growth model the savings rate would come close to $100 \%$ if the elasticity of marginal utility were equal to or smaller than one. Such an "oversaving" would, however impose an unduly high and ethically indefensible burden on earlier generations. Moreover, elasticities of marginal utility below one would entail some violation of the principle of "circumstance solidarity" 2 : Any increase in the productivity of capital would harm the earlier generations through imposed higher savings in the optimal solution although the technical progress would allow for a Pareto improvement for all generations. In the case of an infinite number of periods, $\eta(c)>1$ moreover is required to make the utility sum converge without accepting pure utility time discount which would give future generation less weight in social evaluation and thus give them an unfair treatment ex ante.

For Weitzman (2009c) [26] $\eta(c)=1$ represents the "lowest lower bound" for acceptable levels of relative risk aversion, and in empirical studies on the costs and benefits of climate change assuming $\eta \geq 1$ is the rule and not the exeption ${ }^{3}$. Therefore we can conclude that one would have to assume an implausibly low and ethically contestable degree of risk aversion to exclude TCR.

Concerning boundedness properties there clearly is a sharp dichotomy between utility functions: Either they are bounded from below or not. Whereas for all utility functions that are unbounded below TCR is inevitable according to Proposition 1, boundedness from below generates the opposite result. In this case only the outcome in the non-catastrophic states eventually counts when the probability of the catastrophic state goes to zero. This is shown by the following Proposition.

\footnotetext{
${ }^{2}$ (see Fleurbaey 2008 [10], for a general discussion of this criterion and Buchholz and Schumacher 2010 [4], for an application to the intergenerational context)

${ }^{3}$ (see Stern 2006 [22], where the mainly used value of constant relative risk aversion is $\eta=1$, or Nordhaus 2008 [18], where $\eta=2$ is applied)
} 
Proposition 2 Assume that the utility function $u(c)$ is bounded below. Then for any sequence of projects $\left(P_{c}^{(n)}\right)_{n \in \mathbb{N}}$ as defined above, expected utility converges to expected utilty without catastrophic risk $\sum_{i=1}^{k} \bar{p}_{i} u\left(\bar{c}_{i}\right)$ if the catastrophic payoff $c_{k+1}^{(n)}$ is bounded from above.

Proof. This follows since $\lim _{n \rightarrow \infty} p_{k+1}^{(n)}=0$ implies $\lim _{n \rightarrow \infty} p_{k+1}^{(n)} c_{k+1}^{(n)}=0$ as $\left(c_{k+1}^{(n)}\right)_{n \in \mathbb{N}}$ is bounded from above and $\lim _{n \rightarrow \infty} p_{i}\left(p_{k+1}^{(n)}\right)=p_{i}$ for all $i=1, \ldots, k$.

Combining Proposition 1 and Proposition 2 shows that EU theory cannot help falling from one extreme into the other, i.e. either to have, in the limit, dominance of the catastrophic risk or to neglect it completely. No way in between is viable that, in the framework of EU theory, would allow for a compromise between both extremes that conforms to ethical intuition: Give bad outcomes with low probabilities some attention but not too much. This shows that application of EU theory makes it impossible to reconcile two "beliefs" on the adequate treatment of catastrophic risks that have been articulated by Ikefuji et al. (2010, 3 - 4 [14]): "Catastrophic risks are important" on the one hand and "the price to reduce catastrophic risks is finite" on the other! 


\section{The Tyranny of Catastrophic Risks for Given Probability Distributions}

The potential dominance of catastrophic risks in the case of utility functions that are not bounded from below is also reflected by an another insight which is related to Proposition 1. This additional result, however, does not refer to sequences of projects as in our previous analysis but, in a situation with an infinite number of states, to a single probability distribution of payoffs and is thus more in the tradition of the existing literature (see Chichilnisky 2000 [5] and 2009 [6] or Weitzman 2009 [25]).

Proposition 3 Let the underlying utility function be unbounded from below. Then there always exists a risky project $P^{\infty}=\left(\bar{c}_{i}, \bar{p}_{i}\right)_{i \in \mathbb{N}}$ with infinitely many outcomes $i=1,2, \ldots$ for which the expected utility value of payoffs is finite but expected utility is infinite.

Proof. Without loss of generality it can be assumed that $\sup _{c>0} u(c) \geq 0$. We choose some $\alpha \in(0,1)$. In order to construct a discrete probability distribution let, for any $i \in \mathbb{N}$, a payoff level $\bar{c}_{i}$ be given by $u\left(\bar{c}_{i}\right)=-2^{\frac{i+1}{\alpha}}$. The existence of each $\bar{c}_{i}$ follows from the assumptions that $u(c)$ has no lower bound and is continuous. Similar as in the proof of Proposition 1, now define probabilities by letting $\bar{p}_{i}:=\left(-u\left(c_{i}\right)^{-\alpha}\right)=2^{(-i+1)}$ for any $i \in \Re$. Since $\sum_{i=1}^{\infty} \bar{p}_{i}=$ $\sum_{i=1}^{\infty} 2^{-(i+1)}=1$ a probability distribution of payoffs is obtained in this way. The sequence of payoffs $\left(\bar{c}_{i}\right)_{i \in \mathbb{N}}$ is decreasing in $i$ and converges to 0 . Therefore, on the one hand we have $\sum_{i=1}^{\infty} \bar{p}_{i} \bar{c}_{i}<\left(\sum_{i=1}^{\infty} \bar{p}_{i}\right) \bar{c}_{1}<\infty$, i.e. the expected value of payoffs is finite. On the other hand, we have $\bar{p}_{i} u\left(\bar{c}_{i}\right)=-\left(-u\left(\bar{c}_{i}\right)\right)^{(1-\alpha)}$ for all $i \in \mathbb{N}$ such that $\lim _{i \rightarrow \infty} \bar{p}_{i} u\left(\bar{c}_{i}\right)=-\infty$ and thus $\sum_{i=1}^{\infty} \bar{p}_{i} u\left(\bar{c}_{i}\right)=-\infty$.

The result in Proposition 3 might appear to be in some contrast to that of Arrow (1974) who has shown that a finite expectation of payoffs always entails finiteness of expected utility if the utility function is concave. But, more or less implicitly and without further discussions, Arrow (as Chichilnisky 2000 [5] and 2009 [6]) has excluded utility functions that are unbounded below from the beginning. His focus instead has been, in the tradition of Menger (1934) [17], on (non-)boundedness of utility functions from above, which is of particular importance in growth theory to ensure discrimination between feasible consumption paths. In this context it is also important to note that for all isoelastic util- 
ity functions except the logarithmic one non-boundedness below (which causes TCR) is equivalent to boundedness above (which is the standard assumption in EU theory, see Arrow, 1971).

In the probability distribution that is constructed in the proof of Proposition 3 , the sequence of probabilities $\left(\bar{p}_{i}\right)$ converges to zero. So again it is the occurrence of very rare events with a bad outcome by which expected utility is driven down to minus infinity if utility is not bounded below. In this sense, Proposition 3 can be interpreted as another variant of the TCR phenomenon and Weitzman's dismal theorem.

In view of Proposition 3 one might wonder whether for a fixed probability distribution of payoffs over an infinite number of states a specific choice of the utility function could prevent expected utility to become infinite. On the one hand, this is trivially true since any utility function that is bounded below always gives a finite value of expected utility. This e.g. holds true for exponential utility functions and for the Burr utility functions that both have $u(0)=0$ (see especially Ikefuji et al. 2010 [14] for an application of such utility functions to catastrophic risks). But if on the other hand one applies the ethically more appealing utility functions that have a degree of relative risk aversion nowhere below one, as suggested here, a negative result is obtained again. To show this we use the procedure as described in the proof of Proposition 3, to construct a probability distribution of payoffs taking $u(c)=\ln c$ as the utility function. Then expected utility not only becomes infinite for this specialy utility function whose relative risk aversion is $\eta=1$ but also for all other utility functions that have an overall higher risk aversion, especially for all isoelastic utility functions with constant elasticity of marginal utility $\eta>1$. Therefore we can conclude that probability distributions with finite expected value of payoffs exist such that, for all utility functions with reasonable high degrees of risk aversion expected utility will not be finite. This once again shows the restricted capability of EU theory to cope with TCR. 


\section{Conclusion}

This paper has made a simple case against the suitability of EU theory to take with the TCR phenomenon into account, i.e. to avoid dominance of very bad but unlikely events in project evaluation: If the underlying vNM utility function is unbounded below always situations can be found in which TCR prevails and the price to prevent catastrophic losses may become too high. In the framework of EU theory the obvious solution would be to adopt utility functions that are bounded below. Then, however, catastrophic events with a low probability no longer have any significant impact on decisions such that the child is thrown out with the bath. Moreover, adopting utility functions that are bounded below is tantamount to assuming implausibly low and ethically non-acceptable degrees of relative risk aversion .

The alternative either is to amend EU theory, e.g. by introducing certain threshold levels (see e.g. Baumgärtner et al., 2008 [3]), or to leave EU theory instead applying some variant of non-expected utility theory ${ }^{4}$ or Kriysiak (2009 [16]). The intention of most of these approaches, however, is to give catastrophic risks more attention instead of less such that the TCR might even be aggravated. So, concerning possible solutions of the TCR problem, one should not expect too much from these alternatives to EU theory that have yet been proposed. A straightforward an unambiguous way out of the TCR dilemma not yet seems to exist.

\footnotetext{
${ }^{4}$ (see Sugden 1997 [23]). For a general review of such approaches see Sugden 1997 [23] and Shaw and Woodward 2008 [21] for a discussion of their potential relevance for environmental economics or other decision criteria as, e.g., that developed by Chichilnisky (2000 [5] and 2009 [6])
} 


\section{References}

[1] Allais M. (1953), "Le comportement de lhomme rationnel devant le risque: critique des postulats et axiomes de lcole Amricaine", Econometrica, Vol. 51, pp. $503-546$

[2] Arrow K.J. (1963), "Aspects of the Theory of Risk Bearing"

[3] Baumgärtner S., Becker C., Frank K., Müller B. and Quaas M. (2008), "Relating the philosophy and practice of ecological economics: The role of concepts, models, and case studies in inter- and transdisciplinary sustainability research", Ecological Economics, Vol. 67 (3),pp. 384 - 393

[4] Buchholz W. and Schumacher J. (2010), "Discounting and welfare analysis over time: Choosing the $\eta "$ ", European Journal of Political Economy (forthcoming)

[5] Chichilnisky G. (2000), "An axiomatic approach to choice under uncertainty with Catastrophic risks", Resource and Energy Economics Vol. 22 (3), pp. 221231.

[6] Chichilnisky G. (2009), "Topology of Fear", Journal of Mathematical Economics, Vol. 45 (12), pp. 807 - 816

[7] Dasgupta P. (2008), "Discounting Climate Change", Journal of Risk and Uncertainty, Vol. 37 (2 - 3), pp. 141 - 169

[8] Dietz S. and Maddison D.J. (2009), "New Frontiers in the Economics of Climate Change", Environmental and Resource Economics, Vol. 43, pp. $295-306$

[9] Ellsberg D. (1961), "Risk, ambiguity and the Savage axioms", Quarterly Journal of Economics, Vol. 75, pp. 643 - 669

[10] Fleurbaey M. (2008), "Justice, Political Liberalism and Utilitarianism: Themes from Harsanyi and Rawls", Cambridge University Press(co-editors: M. Salles, J. Weymark)

[11] Gollier C. (2001), "The Economics of Risk and Time", MIT Press Cambridge USA 
[12] Harsanyi J.C. (1955), "Cardinal Welfare, Individualistic Ethics, and Interpersonal Comparisons of Utility", Journal of Political Economy, Vol. 63 (4), pp. $309-321$

[13] Heal G. (2008), "Climate Economics: A Meta-Review and Some Suggestions for Future Research", Review of Environmental Economics and Policy, Vol. 3 (1), pp. 421

[14] Ikefuji, M., R.J.A. Laeven, J.R. Magnus, and C. Muris (2010), "Expected Utility and Catastrophic Risk", Working Paper, Tilburg University

[15] Kahneman D. and Tversky A. (1979), "Prospect Theory: An Analysis of Decision Under Risk", Econometrica Vol. 47, March, pp. 263-291

[16] Krysiak F. (2009), "Sustainability and its relation to efficiency under uncertainty", Economic Theory, Vol. 41 (2), pp. 297-315

[17] Menger K. (1934), "Das Unsicherheitsmoment in der Wertlehre. Betrachtungen in Anschluss an das sogenannte Petersburger Spiel", Zeitschrift für Nationalökonomie 5

[18] Nordhaus W. (2008), "A Question of Balance", Yale Universtiy Press

[19] Rabin M. (2000), "Risk Aversion and Expected-Utility Theory: A Calibration Theorem", Econometrica, Vol. 68 (5), pp. 1281 - 1292

[20] Roemer J. (1996), "Theories of Distributive Justice", Cambridge, MA: Harvard University Press.

[21] Shaw D.W. and Woodward R.T. (2008), "Why environmental and resource economists should care about non-expected utility models", Resource and Energy Economics, Vol. 30 (1), pp. 66 - 89

[22] Stern N. (2006), "The Economics of Climate Change: The Stern Review", Cambridge University Press

[23] Sugden R. (1997) ,"Alternatives to expected utility theory: Foundations and concepts", in: Handbook of Expected Utility Theory, Eds. S. Barber'a, P.J. Hammond and C. Seidl, Kluwer, Boston, Mass. 
[24] Weitzman M. (2009a), "On Modeling and Interpreting the Economics of Catastrophic Climate Change", The Review of Economics and Statistics, Vol. 91 (1), pp. 1 - 19

[25] Weitzman M. (2009b), "Reactions to the Nordhaus Critique", Harvard University Working Paper

[26] Weitzman M. (2009c), "How Should the Distant Future be Discounted When Discount Rates are Uncertain?", Harvard University Working Paper 